\title{
Disseminação de discursos de ódio em comentários de notícias: uma análise a partir de notícias sobre o universo LGBT em cibermeios sul-mato-grossenses no Facebook ${ }^{1}$
}

Hate speech dissemination in news comments: analysis of news about LGBT universe on Facebook cybermedia from Mato Grosso do Sul

Difusión del discurso de odio en los comentarios de las noticias: un análisis de las noticias sobre el universo LGBT en los cibermedios de Mato Grosso do Sul en Facebook

DOI: https://doi.org/10.1590/1809-5844202127

\section{Marcos Paulo da Silva ${ }^{1}$}

http://orcid.org/0000-0003-2868-4865

Lucas Souza da Silva ${ }^{1}$

http://orcid.org/0000-0003-1646-0178

${ }^{1}$ (Universidade Federal de Mato Grosso do Sul, Faculdade de Artes, Letras e Comunicação, Programa de PósGraduação em Comunicação. Campo Grande - MS, Brasil).

\section{Resumo}

O artigo ancora-se na hipótese de fundo de que nenhuma modalidade de discurso se dissemina socialmente se não encontrar respaldo em padrões culturais mais amplos pavimentados na vida cotidiana. Nesse sentido, busca-se analisar as modalidades de manifestação do discurso de ódio contra a população LGBT nos comentários de publicações de notícias na plataforma Facebook no cenário de Mato Grosso do Sul. O trabalho aborda o contexto de constituição das redes sociais, a crescente apropriação desses espaços pelas empresas jornalísticas para a veiculação de notícias e as consequências desses fenômenos na manifestação de discursos de ódio. Apresenta-se uma análise qualitativa e quantitativa dos comentários classificados como discursos de ódio nas publicações de nove notícias dos três principais cibermeios sul-mato-grossenses - Campo Grande News, Midiamax e Correio do Estado. Em um universo total de 1.784 comentários destas publicações, 477 foram classificados como discurso de ódio, com prevalência das categorias "repulsa pela existência ou repúdio pelas atitudes das pessoas LGBT” e “descrédito da informação jornalística”.

Palavras-chave: Comunicação. Jornalismo. Redes sociais. Discurso de ódio. Mato Grosso do Sul.

1 Parte das discussões deste trabalho foram apresentadas no XVII Encontro Nacional da Associação Brasileira de Pesquisadores em Jornalismo, 6 a 8 de novembro de 2019, Goiânia (GO). O material empírico analisado no artigo teve origem em pesquisa contemplada pelo Prêmio Adelmo Genro Filho de Pesquisa em Jornalismo 2019, categoria Iniciação Científica. Trabalho realizado com apoio da Coordenação de Aperfeiçoamento de Pessoal de Nível Superior - Brasil (Capes) - Código de Financiamento 001. 


\begin{abstract}
This paper is based on the background hypothesis that no discourse modality spreads socially if it is not supported by broader cultural patterns paved in everyday life. The goal is to analyze the modalities of the hate speech against the LGBT population in comments of news posts on Facebook platform in the Mato Grosso do Sul context. The research addresses the scenario of the constitution of social networks, the increasing appropriation of these spaces by journalistic companies for the dissemination of news and the consequences of these phenomena in the manifestation of hate speech. The paper presents a qualitative and quantitative analysis of comments classified as hate speech in the nine news posts of the three main cybermedia from Mato Grosso do Sul - Campo Grande News, Midiamax e Correio do Estado. Within a total universe of 1.784 comments from these publications, 477 were classified as hate speech, with the prevalence of the categories "repulsion for the existence or repudiation of LGBT people’s attitudes” and “discrediting journalistic information”.
\end{abstract}

Keywords: Communication. Journalism. Social networks. Hate speech. Mato Grosso do Sul.

\title{
Resumen
}

El artículo se basa en la hipótesis de fondo de que ninguna modalidad de discurso se extiende socialmente si no está respaldada por patrones culturales más amplios pavimentados en la vida cotidiana. En este sentido, la investigación busca analizar las modalidades de manifestación del discurso de odio contra la población LGBT en los comentarios de publicaciones de noticias en la plataforma Facebook en el escenario Mato Grosso do Sul. El artículo aborda el contexto de la constitución de redes sociales, la creciente apropiación de estos espacios por parte de las empresas periodísticas para la difusión de noticias y las consecuencias de estos fenómenos en la manifestación del discurso de odio. El estudio presenta un análisis cualitativo y cuantitativo de los comentarios clasificados como discurso de odio en nueve publicaciones de noticias de los tres principales cibermedios en Mato Grosso do Sul - Campo Grande News, Midiamax e Correio do Estado. De un universo total de 1.784 comentarios de estas publicaciones, 477 se clasificaron como discurso de odio, con la prevalencia de las categorías "repulsión por la existencia o repudio de las personas LGBT” y “desacreditación la información periodística”.

Palabras-clave: Comunicación. Periodismo. Redes sociales. Discurso de odio. Mato Grosso do Sul.

\section{Introdução}

A presente reflexão ancora-se, como hipótese de fundo, no entendimento de que o processo de enfraquecimento dos contratos simbólicos instituídos historicamente em torno da autoridade jornalística (VOS; THOMAS, 2018) encontra respaldo em padrões culturais mais amplos, consolidados na contemporaneidade, que remetem à erosão de credibilidade de um rol mais abrangente de instituições sociais modernas, entre elas a justiça, a escola formal, a ciência e a própria democracia. Volta-se, assim, ao contexto de constituição das redes sociais na Internet e à crescente apropriação desses espaços pelas empresas jornalísticas para a veiculação de notícias, bem como às consequências desses fenômenos na manifestação 
de discursos de ódio, em especial no espaço demarcado pela regionalidade de Mato Grosso do Sul. A escolha temática não ocorre por acaso. De acordo com o Mapa da Violência de Gênero², a taxa nacional de violência contra pessoas trans em 2017 foi de dois casos a cada 100 mil habitantes, com oito Estados acima da média nacional: Tocantins (9), Roraima (7), Acre (5), Mato Grosso do Sul (5), Minas Gerais (4), Amapá (3), Alagoas (3) e São Paulo (3). Mato Grosso do Sul foi o Estado com maior taxa de violência contra pessoas homossexuais ou bissexuais em 2017: 91 a cada 100 mil habitantes, mais do que o dobro da taxa nacional, de 41 por 100 mil.

Do ponto de vista metodológico, adota-se como recorte empírico os comentários postados na rede social Facebook nas fanpages ${ }^{3}$ dos três ciberjornais com a maior popularidade em Mato Grosso do Sul: Correio do Estado, com 495 mil curtidas e 493 mil seguidores; Campo Grande News, com 489 mil curtidas e 514 mil seguidores; e Midiamax, com 387 mil curtidas e 393 mil seguidores ${ }^{4}$. Para constituição do corpus do estudo, valese de uma amostragem não-probabilística de representatividade social (LOPES, 2005, p. 145). Na prática, foram selecionadas três matérias de cada veículo no período entre 9 de julho de 2016 e 28 de agosto de 2018, cujas temáticas tratassem de temas relacionados ao universo LGBT e que tivessem mais de 200 reações e 50 comentários nas publicações das notícias nas fanpages dos três ciberjornais. A seleção das nove matérias, além da quantidade mínima já citada de reações e comentários, também adotou como pré-requisito fundamental as publicações que deram enfoque exclusivo às questões LGBT ${ }^{5}$, bem como a busca por temas diversificados que abrangessem a complexidade dos grupos inseridos nas siglas da expressão LGBT e que tratassem da temática da homossexualidade em diferentes cenários e abordagens.

O objetivo diante da temática escolhida foi estabelecer uma categorização quantitativa e qualitativa dos comentários analisados e discutir os resultados obtidos à luz das características dos processos contemporâneos de disseminação de informações nas redes sociais. Trata-se, portanto, para além de uma questão temática socialmente relevante, de uma reflexão voltada, em essência, ao cerne dos processos jornalísticos contemporâneos. Ressalta-se também a ressalva de que, embora se trabalhe com a nomenclatura "discurso" no interior do conceito de discurso de ódio, o estudo não pretende desenvolver propriamente uma análise discursiva, uma vez que se vale da perspectiva metodológica da análise de conteúdo (BARDIN, 2009). Ademais, adota-se como referência o conceito de "discurso de ódio” em detrimento de outras concepções, como “cultura de ódio” (MONDRAGÓN, 2009, QUADROS, 2018) ou “incivilidade online” (CHEN, 2018), uma vez que tais definições

2 Disponível em: https://mapadaviolenciadegenero.com.br/lgbt/. Acesso em: 15 ago. 2020.

3 Página específica dentro do Facebook direcionada para empresas ou marcas.

4 Acesso em 15 de agosto de 2020.

5 São muitas as representações envolvidas, além das várias mudanças na sigla representativa desse movimento no Brasil. A primeira utilizada, GLS (Gays, Lésbicas e Simpatizantes) foi substituída por LGBT na I Conferência Nacional LGBT, realizada em 2008. A IV conferência nacional, a mais recente, realizada em novembro de 2019, ainda utiliza essa sigla. Há controvérsias quanto à nomeação de todos os Ts, a inclusão de um Q (para queers) ou um A (para assexuais), um I (para intersexos), mas há consenso na busca por inclusão das mais variadas dimensões da construção das desigualdades trazendo à tona pertencimentos sexuais e de gênero. 
incluem outras modalidades de fenômenos controversos nas redes sociais para além da discursividade, os quais não constituem objeto da análise em tela.

\section{Internet, redes e transformação nos processos jornalísticos}

As interfaces entre a dinâmica das redes sociais na Internet e a transformação nos processos jornalísticos têm sido objeto de vasta literatura acadêmica. As reflexões perpassam os debates da desinformação (SOARES et al., 2019, RECUERO; GRUZD, 2019), da comunicação política (SAINZ; RECUERO, 2019), da polarização ideológica nas redes (RECUERO; ZAGO; SOARES, 2019) e da disseminação de discursos de negação da alteridade (QUADROS, 2018), como nos casos de propagação de discursos de ódio, aportando na própria reconfiguração das linguagens jornalísticas (CANAVILHAS, 2011, ZAGO, 2017, LONGHI, 2019).

A autora boyd (2007, p. 2) define os sites de redes sociais como uma geração de "públicos mediados”, isto é, ambientes nos quais as pessoas podem se reunir publicamente por meio de tecnologias de mediação. Embora reconheça que existam similitudes com as interações do universo não mediado (os interlocutores podem ampliar o círculo de interação se a conversa for interessante ou ignorá-lo caso não seja, por exemplo), a pesquisadora destaca quatro características peculiares das conversações em rede na dinâmica do ciberespaço. Segundo boyd (2007), os principais aparatos que viabilizam a dinâmica do método de conversação em rede são a persistência (persistence), a buscabilidade (searchability), a replicabilidade (replicability) e as audiências invisíveis (invisible audiences). A persistência relaciona-se com o registro das conversações pelas ferramentas técnicas das redes, ou seja, conforme o indivíduo se comunica em redes sociais, as mensagens são armazenadas pelo sistema e persistem naquele espaço, "a menos que exista uma ação no sentido de excluílas” (RECUERO, 2013, p. 116). A segunda característica é intrínseca à primeira. Tratase da buscabilidade, uma vez que devido ao armazenamento das mensagens, estas podem ser recuperadas e pesquisadas a qualquer momento pelos mecanismos de software que possibilitam a recuperação de informações processadas em rede.

A replicabilidade, por sua vez, refere-se à facilidade com que as mensagens podem ser reproduzidas por outros atores e, dessa forma, "espalham-se nas redes entre os diversos grupos, migram e tornam-se conversações cada vez mais públicas, moldam e expressam opiniões, geram debates e amplificam ideias” (RECUERO, 2013, p. 116). A última característica, definida como audiências invisíveis, relaciona-se com a replicabilidade das mensagens e na extensão das mesmas para além dos atores da conversação. Propicia, nesse sentido, a possibilidade de participação de centenas de pessoas com milhares de interações que são acessíveis por todos os atores, espalhando-as e fazendo com que migrem entre os grupos e entre os sites de redes sociais (RECUERO, 2013). Essas quatro características constituem um cenário fundamental e fértil para a transmissão de informações, já que depois da veiculação das mensagens, as informações permanecem no ciberespaço, podendo 
ser localizadas pelos mecanismos de buscabilidade e replicadas pelos indivíduos em rede para uma audiência invisível, que atinge uma larga escala de públicos com características e culturas distintas (RECUERO, 2007).

Tal cenário é apropriado pelo jornalismo, que identifica nas redes sociais o terreno propício para a propagação de notícias em larga escala, utilizando das características da conversação em rede e reinventando suas práticas nas plataformas tecnológicas de comunicação midiática (CANAVILHAS, 2011, ZAGO, 2017, LONGHI, 2019). De acordo com Canavilhas (2011), algumas das consequências para o jornalismo dessa apropriação do ciberespaço são o virtual aumento da audiência e a possibilidade de fortalecimento do vínculo com os leitores, transformando a audiência em comunidade. Para o autor português, as redes sociais facilitam uma troca na forma como os usuários se relacionam com os meios de comunicação, revigorando os vínculos pelo desenvolvimento do sentimento de pertencimento a uma comunidade.

Nesse vértice, segundo Recuero (2007), as redes sociais na internet funcionam como fontes, filtros ou como espaços de reverberação das informações. As redes atuam de maneira complementar à função jornalística, não apresentando o mesmo comprometimento deontológico, mas auxiliando na mobilização de pessoas, na construção de discussões e mesmo no apontamento de diversidades de pontos de vista a respeito de um determinado assunto. A reverberação dos conteúdos jornalísticos nas redes sociais, conforme debate Recuero (2007), pode agregar confiabilidade às informações, uma vez que indica a relevância do conteúdo para uma comunidade, atribuindo valor às notícias dentro das comunidades instituídas em rede. "As informações disponibilizadas nos sites de rede social tornam-se mais acessíveis, menos privadas, mais circulantes” (RECUERO, 2014, p. 117).

As redes sociais como o Facebook, por exemplo, disponibilizam em suas plataformas as condições necessárias para que seus usuários emitam opinião. “Também acrescentam comentários e novas análises, envolvendo os usuários como também produtores das informações” (RECUERO, 2007, p. 12). Nesse sentido, as publicações do Facebook concedem espaço para que os usuários da rede social reajam de várias maneiras às postagens de conteúdo veiculadas pelas páginas de notícias. Diante desta relativa autonomia propiciada por um espaço descentralizado e sem muitas regras definidas - seja pela plataforma das redes sociais, o que facilita a interatividade dos usuários, seja pelo jornalismo, que utiliza do alcance destas redes para veicular informações - tem-se um cenário propenso para a propagação de uma multiplicidade de comentários em rede, sem prévio controle ou moderação. Não por acaso, fenômenos contemporâneos como a desinformação (SOARES et al., 2019, RECUERO; GRUZD, 2019), a polarização ideológica (RECUERO; ZAGO; SOARES, 2019) e a disseminação de discursos de negação da alteridade (QUADROS, 2018) têm recebido lastro na dinâmica reticular do ciberespaço. O fenômeno do discurso de ódio propagado nos comentários de publicações de notícias no Facebook, nesse ínterim, assume caráter central em relação aos danos e às violações de direitos fundamentais das vítimas desta prática, como a população LGBT, objeto de reflexão desta análise. 


\section{Discurso de ódio e aderência às características das redes}

Originada do inglês hate speech, a expressão "discurso de ódio" refere-se, de acordo com Brugger (2007, p. 118), a "palavras que tendem a insultar, intimidar ou assediar pessoas em virtude de sua raça, cor, etnicidade, nacionalidade, sexo ou religião, ou que têm a capacidade de instigar violência, ódio ou discriminação contra tais pessoas”. Sarmento (2006, p. 54-55) define o fenômeno como "manifestações de ódio, desprezo ou intolerância contra determinados grupos, motivadas por preconceitos ligados à etnia, religião, gênero, orientação sexual, dentre outros fatores”. Por seu turno, Meyer-Pflug (2009, p. 97) delineia a prática como a manifestação de "ideias que incitam a discriminação racial, social ou religiosa em determinados grupos, na maioria das vezes, as minorias”. De forma particular, para Rios (2007), o discurso de ódio direcionado à população LGBT constitui o efeito de uma ordem heteronormativa que estabelece uma diferenciação entre os sujeitos e cria um sistema de hierarquização no qual as pessoas LGBT são categorizadas como "anormais”. Da mesma maneira, tal construção constitui um mecanismo utilizado há séculos para manter estes setores à margem do direito comum, inscrevendo-os em regimes de exceção.

Crime abominável, amor vergonhoso, gosto depravado, costume infame, paixão ignominiosa, pecado contra a natureza, vício de Sodoma. Para Borrillo (2010, p. 13), essas são algumas de incontáveis ofensas direcionadas àqueles que não se enquadram no padrão único e aceitável socialmente: a heterossexualidade. Segundo o autor, essa diferença homo/hétero tem por objetivo "ordenar um regime das sexualidades em que os comportamentos heterossexuais são os únicos que merecem a qualificação de modelo social e de referência para qualquer outra sexualidade” (BORRILLO, 2010, p. 16). Em decorrência desse comportamento, a homofobia e o discurso de ódio contra a população LGBT tornam-se "guardiãs" das fronteiras tanto sexuais (homo/hétero) quanto de gênero (masculino/feminino).

A Constituição Brasileira de 1988, documento por sua vez amparado na Declaração Universal dos Direitos Humanos de 1948, assegura os direitos do cidadão e dos meios de comunicação quanto à livre manifestação do pensamento, da expressão e da informação. Tais preceitos servem de parâmetro para a emissão de opiniões, pensamentos e posicionamentos políticos nos espaços públicos. Com a atomização das redes sociais, todavia, nas quais se enquadra o Facebook, os usuários - dispostos no ciberespaço - compartilham opiniões em seus perfis pessoais que potencialmente alcançam de forma instantânea toda uma comunidade que pode confirmar ou contrariar aquela ideia exposta. Um dos principais entraves emerge quando as opiniões manifestadas ferem a dignidade humana do grupo social ao qual a publicação faz referência. A mesma Constituição que relega a liberdade de expressão também assegura o direito à dignidade para grupos historicamente mais frágeis e propensos a sofrer discriminação e preconceito, como a população LGBT.

O Facebook permite uma expressão comunicativa com mediação algorítmica, mas sem cerceamento direto, o que concede margem a ambiguidades entre a liberdade de 
expressão e o discurso de ódio. Nesse ínterim, paradoxalmente, as redes sociais passam a configurar um potencial locus hostil ao debate jornalístico, sobretudo no que tange o universo de minorias sociais como a população LGBT. De acordo com informações institucionais do próprio Facebook, 2,5 milhões de postagens foram removidas após denúncias apenas no primeiro trimestre de 2018, número que subiu para 3,3 milhões nos últimos três meses do ano (FACEBOOK, 2019).

\section{Modalidades de discurso de ódio em publicações de notícias}

Como forma de viabilizar as reflexões anteriormente anunciadas, adota-se como recorte empírico os comentários de nove publicações de notícias localizadas na plataforma de comentários das páginas no Facebook dos três mais populares cibermeios de Campo Grande, capital de Mato Grosso do Sul, que juntos somam mais de 1,2 milhão de seguidores: Campo Grande News, Correio do Estado e Midiamax. Para tanto, utiliza-se a metodologia de Análise de Conteúdo (AC) proposta por Bardin (2009). Vale-se inicialmente de uma abordagem quantitativa das interações e de uma posterior verificação qualitativa dos comentários das publicações de notícias analisadas no Facebook. Neste segundo caso, a pesquisa efetua-se a partir de categorias elaboradas durante a pré-análise com base no aporte bibliográfico.

Na prática, foram selecionadas três matérias de cada veículo no período entre 9 de julho de 2016 e 28 de agosto de 2018, cujas temáticas tratassem de temas relacionados ao universo LGBT, conforme apresentado na Tabela 1. Para a seleção das matérias, foi utilizado o mecanismo de busca do próprio Facebook. Por opção metodológica, os termos pesquisados no dispositivo de procura da rede social foram: "LGBT (s)", "lésbica (s)”, "gay (s)”, "bissexual (s)”, “travesti (s)”, “transexual (s)”, "transgênero (s)”, "homossexual (s)”, "homossexualidade”, "homofobia” e "LGBTfobia".

Tabela 1 - Caracterização quantitativa do corpus de estudo

\begin{tabular}{|c|c|c|c|c|c|}
\hline Título da notícia & Data & Cibermeio & Reações & Comentários & $\begin{array}{l}\text { Caracterização } \\
\text { como discurso } \\
\text { de ódio }\end{array}$ \\
\hline $\begin{array}{l}\text { Carnaval da } \\
\text { diversidade tem } \\
\text { muito beijo, mas } \\
\text { também uma dose de } \\
\text { autocensura }\end{array}$ & 27/02/2017 & $\begin{array}{l}\text { Campo } \\
\text { Grande News }\end{array}$ & 968 & 483 & $24 \%$ \\
\hline $\begin{array}{l}\text { Primeiro casal gay } \\
\text { a contar história no } \\
\text { Lado B vai dar sorte } \\
\text { a quem quer casar }\end{array}$ & 09/06/2016 & $\begin{array}{l}\text { Campo } \\
\text { Grande News }\end{array}$ & 507 & 122 & $31,9 \%$ \\
\hline
\end{tabular}




\begin{tabular}{|c|c|c|c|c|c|}
\hline Título da notícia & Data & Cibermeio & Reações & Comentários & $\begin{array}{l}\text { Caracterização } \\
\text { como discurso } \\
\text { de ódio }\end{array}$ \\
\hline $\begin{array}{l}\text { Na marcha LGBT, } \\
\text { moçada é maioria, } \\
\text { apesar de ainda } \\
\text { sofrerem pressão } \\
\text { dos pais }\end{array}$ & $01 / 10 / 2017$ & $\begin{array}{l}\text { Campo } \\
\text { Grande News }\end{array}$ & 922 & 404 & $11,8 \%$ \\
\hline $\begin{array}{l}\text { Tartaruga mais } \\
\text { velha do mundo } \\
\text { é homossexual e } \\
\text { namora há } 26 \text { anos }\end{array}$ & $24 / 10 / 2017$ & $\begin{array}{l}\text { Correio do } \\
\text { Estado }\end{array}$ & 977 & 236 & $44 \%$ \\
\hline $\begin{array}{l}\text { Concurso irá eleger } \\
\text { os gays mais bonitos } \\
\text { de MS neste sábado }\end{array}$ & 21/09/2017 & $\begin{array}{l}\text { Correio do } \\
\text { Estado }\end{array}$ & 609 & 207 & $15 \%$ \\
\hline $\begin{array}{l}\text { Parada LGBT leva } \\
\text { cores do arco-íris } \\
\text { para o centro de } \\
\text { Campo Grande }\end{array}$ & $26 / 11 / 2016$ & $\begin{array}{l}\text { Correio do } \\
\text { Estado }\end{array}$ & 714 & 111 & $45 \%$ \\
\hline $\begin{array}{l}\text { Em estreia no teatro, } \\
\text { Tammy Miranda } \\
\text { aparece só de cueca } \\
\text { e beija muito no } \\
\text { palco }\end{array}$ & $30 / 05 / 2017$ & Midiamax & 320 & 100 & $52 \%$ \\
\hline $\begin{array}{l}\text { Menino de } 9 \text { anos } \\
\text { comete suicídio após } \\
\text { revelar a colegas de } \\
\text { classe que era gay }\end{array}$ & $28 / 08 / 2018$ & Midiamax & 1216 & 58 & $29 \%$ \\
\hline $\begin{array}{l}5^{\text {a }} \text { parada da } \\
\text { diversidade neste } \\
\text { sábado ressalta luta } \\
\text { contra homofobia }\end{array}$ & 30/09/2017 & Midiamax & 203 & 63 & $34 \%$ \\
\hline
\end{tabular}

Fonte: autores (2019).

O estudo fez o levantamento de 1.784 comentários dispostos nas nove publicações de notícias identificadas na AC. Ao todo, foram constatados 477 comentários classificados como discurso de ódio, o que corresponde a $27 \%$ de todas as interações analisadas.

\section{Categorias de discurso de ódio contra a população LGBT}

Após a análise quantitativa, foram sistematizadas nove categorias de discurso de ódio constituídas a partir das mediações que emergiram entre o referencial teórico estudado 
doenças em uma Assembleia Geral e retirou a classificação, além de extrair a nomeação de "homossexualismo" - o prefixo "ismo" na medicina indica doença. O Conselho Federal de Psicologia do Brasil deixou de tratar a orientação sexual como doença em 1985.

Figura 2 - Exemplos da categoria "Vitimização" observada nos comentários classificados como discurso de ódio

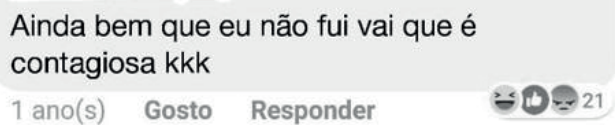

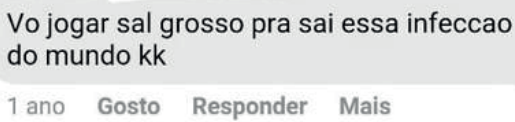

Fonte: comentários extraídos do Facebook para finalidades da pesquisa.

c. Repulsa pela existência ou repúdio pelas atitudes das pessoas LGBT: Embora todas as categorias apresentem ramificações da LGBTfobia, esta primordialmente abrange a maior parte dos comentários ditos homofóbicos. Etimologicamente, a palavra é composta por dois termos distintos: homo, o prefixo de homossexual; e o grego phobos, que significa "medo", "aversão" ou "fobia”. Em outras palavras, LGBTfobia significa aversão, repugnância, medo, ódio, preconceito que algumas pessoas ou grupos nutrem contra homossexuais, lésbicas, bissexuais e transexuais. Se as outras categorias se utilizam de fatores distintos para desvalorizar ou condenar as práticas homossexuais, esta utiliza-se apenas do puro ódio, nojo e abominação contra a população LGBT. Comentários como "nojo", "que horror”, "credo", ou figuras representando vômito foram classificadas nessa categoria de discurso de ódio.

Figura 3 - Exemplos da categoria "Repulsa” observada nos comentários classificados como discurso de ódio

Como seria bom se tivesse terrorismo por aqui pra explodir toda essa putaria

1 ano Gosto Responder Mais

\section{Porquice , fim do mundo \\ 2 ano(s) Gosto Responder}

Fonte: comentários extraídos do Facebook para finalidades da pesquisa.

d. Descrédito da informação jornalística, veículo de comunicação ou redator da notícia: Esta categoria tem como propósito principal dissolver a credibilidade do conteúdo apresentado e deslegitimar a notícia publicada na fanpage. Por se tratar de questões relativas a um grupo minoritário da sociedade, em geral os 
usuários adeptos deste argumento não veem motivos para se pautar conteúdos referentes à população LGBT em uma sociedade majoritariamente heterossexual. Em vista disso, manifestam a posição contrária à temática abordada, julgam o posicionamento político e ideológico do veículo de comunicação e ofendem até mesmo o(a) jornalista que reportou a notícia. Nesta categoria, foram selecionados comentários como “lixo de matéria”, “jornal sem conteúdo”, “fim do jornalismo”, “jornalista comunista” e entre outras manifestações na tentativa de desvalorizar o caráter noticioso da informação.

Figura 4 - Exemplos da categoria "Descrédito da informação jornalística” observada nos comentários classificados como discurso de ódio

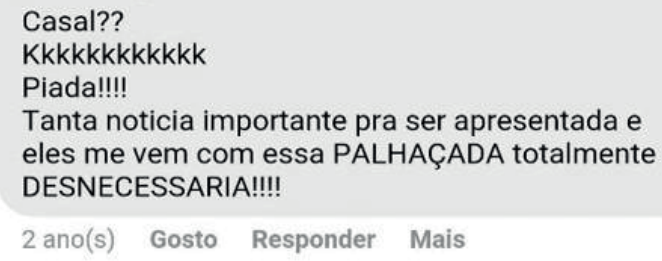

Quantas boas materias para ser postadas, vcs vem com esse lixo de noticia, não sei oque é pior a noticia ou esse CGN?

2 ano(s) Gosto Responder Mais

Fonte: comentários extraídos do Facebook para finalidades da pesquisa.

e. Injúria ou ofensa à dignidade humana: Difere essencialmente da categoria de “repulsa ou repúdio pelas pessoas ou pelos comportamentos da população LGBT" no que diz respeito ao propósito do comentário. Os comentários desta categoria objetivam ferir exclusivamente a dignidade da pessoa. As manifestações de ódio não se estabelecem apenas contra as atitudes e comportamentos do grupo LGBT, mas contra as pessoas, isto é, trata-se de um ataque à identidade e ao ser humano em sua integridade. $\mathrm{O}$ discurso de ódio em questão apresenta comentários com termos "lixos” e "aberrações".

Figura 5 - Exemplos da categoria “Injúria” observada nos comentários classificados como discurso de ódio

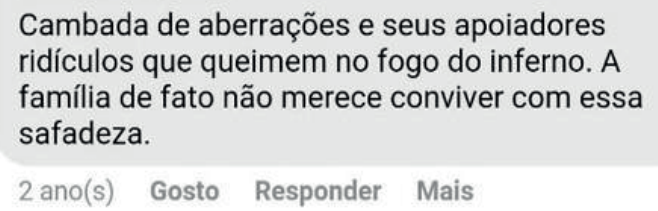

Viados do cabruco que ta na forca ocupando espaca tem aquele misersvel do jeam William encargado do satanas

1 ano Gosto Responder Mais

Fonte: comentários extraídos do Facebook para finalidades da pesquisa. 
f. Imposição da moralidade e da religiosidade pessoal: Esta categoria avalia as publicações sob uma ótica religiosa e moralista que deve estar de acordo com os princípios pessoais do internauta. Mesmo o Brasil constituindo um Estado laico, 86,8\% da população brasileira segue os preceitos e liturgias do cristianismo, segundo o Instituto Brasileiro de Geografia e Estatística (IBGE). Diante desses números e da moral cristã de natureza ortodoxa que historicamente condena as práticas homossexuais, foram observadas diversas manifestações de discursos de ódio justificando o preconceito com a citação de versículos bíblicos e histórias atribuídas à condenação homossexual, como Sodoma e Gomorra (Gênesis, capítulos 18-19). Unida aos ideais religiosos, a moral pessoal também é um dos motivadores do discurso de ódio. Essas regras servem para orientar cada indivíduo, nortear as suas ações e os seus julgamentos sobre o que é moral ou imoral, certo ou errado, bom ou ruim. Foram notados comentários do tipo “casal é homem e mulher”, “inversão de valores”, “família é pai e mãe”, entre outros que colocam a moralidade pessoal como parâmetro a ser seguido.

Figura 6 - Exemplos da categoria “Imposição da religiosidade e da moralidade” observada nos comentários classificados como discurso de ódio

Só seu que quando Jesus voltar eles vão se arrepender de ter sido enganados por esse mundo.

Onde já se viu um homem querer ser mulher. Isso nunca será de Deus.

Olha Sodoma e Gomorra.

Breve será reduzido a nada por essas

aberrações.

Tem que ler a santa palavra e se arrepender de seus pecados.

Assim como tem aqueles que defender

essas asneiras, tem nos que defendemos a verdade.

1 ano Gosto Responder Mais
Deus fez o homem e a mulher ... Não o homem é o homem .....

É falta de tomar vergonha na cara e cumprir com os propósitos de Deus na vidas de vCS...

2 ano(s) Gosto Responder Mais

Fonte: comentários extraídos do Facebook para finalidades da pesquisa.

g. Abordagem biologizante: Este tipo de discurso de ódio foi classificado nos comentários nos quais predominam uma visão biologicista ou que fazem referência a aspectos biológicos. A questão da impossibilidade reprodutiva entre as relações homossexuais tanto na espécie humana quanto no reino animal foi 
um dos argumentos mais utilizados pelos usuários na tentativa de condenar a homossexualidade. Outro fator bastante observado remete aos comentários que atribuem uma eventual "antinaturalidade” às práticas homossexuais, como distúrbio dos princípios que regem as leis da natureza.

Figura 7 - Exemplos da categoria “Abordagem biologizante” observada nos comentários classificados como discurso de ódio

Difícil hein $\because$. .. Todo indivíduo merece ser respeitado mas não tem como dizer $\mathrm{q}$ relacionamento entre o mesmo sexo é NORMAL perante a natureza,genética e o Mundo no seu todo...!?!?!?

2 ano(s) Gosto Responder Mais quando o ser humano ter a capacidade de se reproduzir sem o sexo oposto. garanto que vou acredita que as vezes a pessoa nasce com sexo errado.

1 ano Gosto Responder Mais

Fonte: comentários extraídos do Facebook para finalidades da pesquisa.

h. Apelo à suposta influência comportamental e de pensamento infantojuvenil: A categoria de discurso de ódio em questão apela ao argumento de que a criança é suscetível e propensa a desenvolver comportamentos homossexuais se ela for exposta a um ambiente com pessoas LGBT. A discriminação é velada e fundamentada no princípio de que a criança é pura e não deve ser corrompida em sua formação como pessoa. Em vista disso, os movimentos LGBT e as práticas homossexuais em público são combatidos na justificativa de que as crianças não podem ver tamanha "barbárie” ou irão se tornar iguais e desenvolver práticas atribuídas à homossexualidade.

Figura 8 - Exemplos da categoria “Influência comportamental infanto-juvenil” observada nos comentários classificados como discurso de ódio

9 anos de idade dizendo que é homossexual? Como assim? Não sei não, mas se der uma investigada mais a fundo pode-se descobrir aí não uma convicção mas sim um abuso sexual isso $\operatorname{sim} \ddot{\circ}$

2 meses Gosto Responder Mais
Fica tranquilo meu problema não com q questão pessoa homosextravesgay e sim com as crianças que vem tamanha barbárie na rua...

(1) 2 ano(s) Gosto Responder Mais

Fonte: comentários extraídos do Facebook para finalidades da pesquisa. 
i. Opinião intermediada por citação de autoridade: De todas as categorias, esta é a mais controversa de explicação. Trata-se da menção a fontes supostamente confiáveis, que podem ser um “especialista” no assunto, uma frase dita por alguma liderança política ou religiosa, celebridade ou estudioso, o que remete à possibilidade de categorização dos comentários no interior do contexto em que foram emitidos (uma vez que as enunciações em si, destituídas de contexto, por vezes não remetem diretamente a questões relativas ao ódio). Denotase que intenção desses comentários é valer-se de uma estratégia retórica de convencimento. Nos casos analisados, as citações de autoridade observadas nos comentários são de políticos que historicamente combatem as práticas homossexuais e os direitos da população LGBT, seja nas igrejas ou nos assentos dos poderes executivo e legislativo. As citações acontecem justamente para manifestar a discriminação, livrando-se da autoria direta e terceirizando a opinião com a menção da respectiva autoridade.

Figura 9 - Exemplos da categoria "Discurso de autoridade" observada nos comentários classificados como discurso de ódio

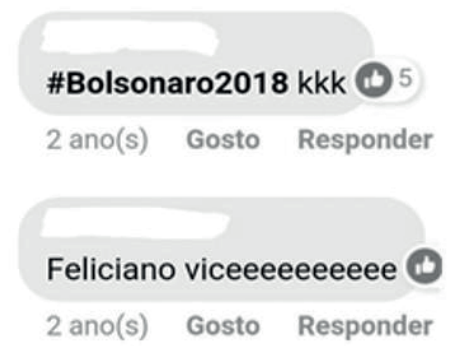

Mitou! Só quero ver quando Bolsomito assumir a presidência e acabar com essa putaria que virou o país! Melhor essas minorias JAIR se acostumando!

1 ano Gosto Responder Mais

Fonte: comentários extraídos do Facebook para finalidades da pesquisa.

O resultado final obtido a partir da categorização dos 477 comentários classificados na pesquisa como manifestações de discurso de ódio contra a população LGBT está relacionado no Gráfico 1: 
Gráfico 1 - Quantificação dos comentários identificados como discurso de ódio nas notícias analisadas

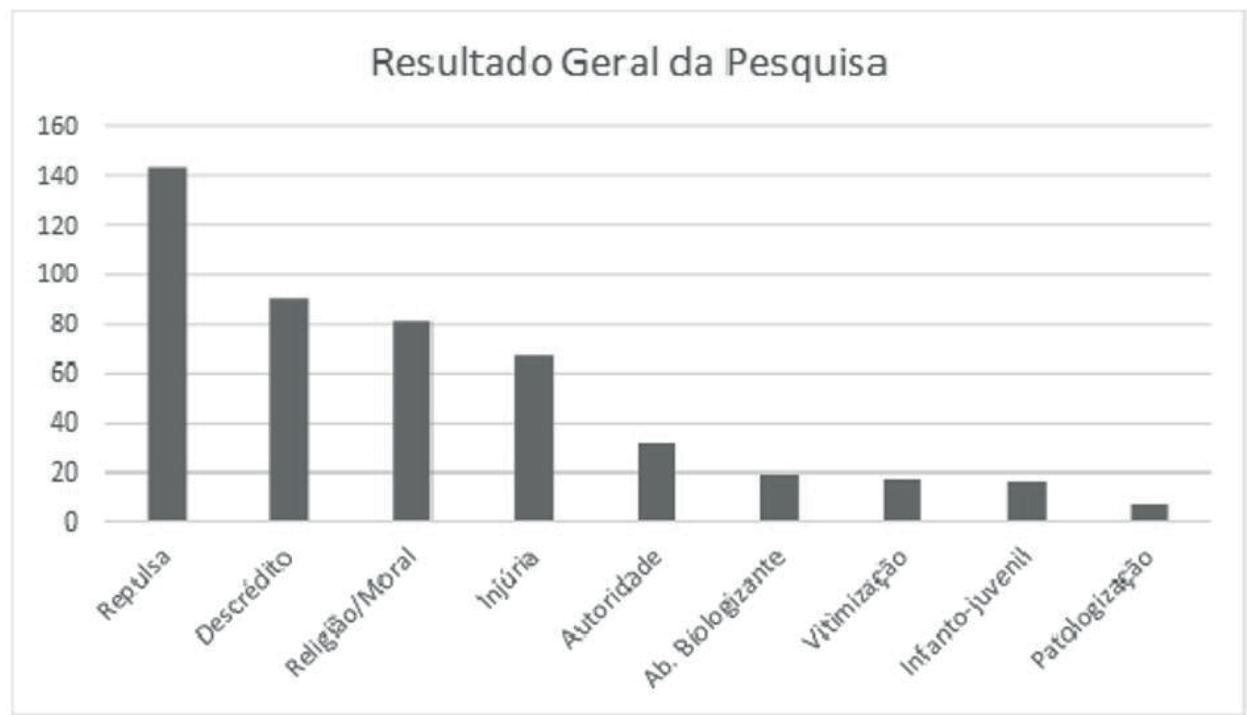

Fonte: autores (2019).

Tal como exposto no gráfico, constata-se que a "repulsa ou o repúdio pelas pessoas e pelo comportamento dos LGBT”, com 144 ocorrências, consiste na categoria mais presente nos 477 comentários identificados como discurso de ódio. Em seguida, encontra-se a categoria “descrédito da informação jornalística”, com 89 ocorrências. Logo na sequência, verificase as categorias "imposição da moralidade e da religiosidade pessoal” (82 ocorrências) e “injúria ou ofensa à dignidade da pessoa humana” (67 ocorrências).

\section{Algumas reflexões finais}

Retoma-se a hipótese de fundo inicialmente apresentada como balizamento da discussão: o entendimento de que o processo de enfraquecimento dos contratos simbólicos instituídos historicamente em torno da autoridade jornalística (VOS; THOMAS, 2018) encontra respaldo em padrões culturais mais amplos, consolidados na contemporaneidade, que remetem à erosão de credibilidade de um rol mais amplo de instituições sociais modernas, entre elas a justiça, a escola formal, a ciência e a própria democracia. À luz da hipótese, a categorização dos dados empíricos obtidos pela pesquisa remete à factibilidade de um conjunto de reflexões.

Nesse sentido, como denotado de forma mais explícita na categorização, não casualmente a modalidade "repulsa ou o repúdio pelas pessoas e pelo comportamento dos LGBT”, identificada em 30\% dos 477 comentários, mostra-se sobressaltada. Trata-se de 
uma manifestação do próprio mecanismo de constituição das redes sociais na Internet, que, segundo Soares et al. (2019, p. 5), pode levar à fragmentação da discussão e à formação de grupos polarizados, ameaçando a própria constituição esfera pública. Para Morato (2017), o ambiente online, em especial as redes sociais, apresentam-se como um espaço atrativo e fomentador do discurso de ódio, pois "a sensação de anonimato e a distância entre os interlocutores [...] se potencializam nas redes sociais reforçando a reprodução da LGBTfobia” (MORATO, 2017, p. 100). Isto é, os sites de redes sociais têm se tornado um lugar privilegiado para a expansão dos extremismos e dos discursos de ódio, especialmente em razão do suposto anonimato para aqueles que imaginam proteger a identidade por detrás de perfis falsos ou da volatilidade das redes que, em geral, permitem que o registro seja eventualmente apagado.

Além do anonimato, outros fatores colaboram para a disseminação de discursos de ódio contra a população LGBT nos comentários de notícias publicadas nas redes sociais. O Facebook permite que pessoas ou grupos alcancem novas audiências, recrutando novos membros e constituindo comunidades - algumas delas voltadas à fomentação de discursos de ódio. Para Recuero (2014), as redes sociais mantêm algumas formas de comunicação em registro potencialmente semiprivado e podem legitimar o discurso de ódio, dando-lhe ressonância, seja através de concordância, apoio, curtidas ou compartilhamentos. Ademais do anonimato e da audiência propiciada por redes sociais como o Facebook, os métodos de conversação em rede, discutidos anteriormente, tais como a buscabilidade, a replicabilidade, a persistência e as audiências invisíveis (boyd, 2007), também potencializam o efeito propagador de discriminação nas redes sociais. O Facebook, por exemplo, expandiu-se de tal forma que ao final de 2017 alcançou mais de 2,13 bilhões de usuários pelo mundo ${ }^{6}$ No Brasil, a rede social ocupa a primeira colocação entre os sites de redes sociais e consiste no site mais visitado pelos usuários brasileiros em todas as classes sociais e faixas de escolaridade, segundo a Pesquisa Brasileira de Mídia de 2015, mantendo-se em primeiro lugar com 83\% dos usuários - inclusive para o consumo de notícias.

Tal quadro remete a um fenômeno sublinhado na contemporaneidade de fragilização - ou de descolamento entre as instâncias formais e a vida cotidiana (HELLER, 1972, SOUZA MARTINS, 2010) - de parâmetros normativos constitucionais oriundos dos tensionamentos históricos das diferentes gerações de direitos de cidadania (SOARES, 2009) - entre eles, os chamados direitos humanos, ratificados pelo documento normativo de 1948 -, o que contribui potencialmente para o acirramento das crises de autoridade da justiça (substituída na semântica dos comentários analisados por uma espécie de justiceirismo) e da própria democracia de massas como projeto histórico civilizatório. Não casualmente, em sintonia com a hipótese de fundo que abre o artigo, Mato Grosso do Sul - locus dos cibermeios analisados - lidera nacionalmente a infeliz estatística de violência contra pessoas

6 Para detalhes, verificar: “Facebook completa 15 anos com 2,3 bilhões de usuários” (G1). Disponível em: https://g1.globo.com/ economia/tecnologia/noticia/2019/02/04/facebook-completa-15-anos-com-23-bilhoes-de-usuarios.ghtml. Acesso em: 15 ago. 2020. 
homossexuais ou bissexuais, com 91 registros a cada 100 mil habitantes, mais do que o dobro da taxa nacional, conforme dados de 2017.

As categorias da "abordagem biologizante" (20 ocorrências), da "influência comportamental infanto-juvenil” (17 ocorrências) e da "patologização” (7 ocorrências), que respondem por aproximadamente $10 \%$ dos comentários, por seu turno, respaldam uma dinâmica mais ampla de crise de autoridade das ciências, o que tem se manifestado também no recente fenômeno de disseminação nas redes sociais dos chamados fake papers - ou artigos científicos com dados falsificados - para finalidades bastante específicas, como no caso dos movimentos antivacina.

Finalmente, faz-se pertinente e necessário analisar a prevalência das categorias “descrédito da informação jornalística” (89 ocorrências) e “opinião intermediada por citação de autoridade” (32 ocorrências), modalidades presentes em um quarto (25\%) dos comentários constituintes do corpus da pesquisa. Nesse cenário, seja por meio da crítica direta ao jornalismo ou pelo questionamento velado da autoridade jornalística por intermédio da citação alternativa de vozes supostamente desautorizadas como fontes na narração noticiosa, constata-se inevitavelmente, por via das formas de interação características das redes sociais, a emergência de um novo vetor no multifacetado ecossistema da crítica de mídia (COELHO, 2019) - senão pela originalidade do fenômeno (a opinião dos enunciatários quase sempre esteve presente nos veículos noticiosos em seções específicas), por sua capilaridade. Entretanto, na contramão do que é apontado como um potencial processo democrático no jornalismo por Canavilhas (2011) e Recuero (2007, 2014), essa nova dinâmica sustenta-se substancialmente em um vértice calcado na repulsa à alteridade.

No que tange especificamente os processos jornalísticos, portanto, remete-se uma vez mais à dinâmica de bipolaridade do modus operandi das redes sociais - em um polo, a instrumentalização do poder de vigilância, a fragmentação das narrativas e formação de bolhas, entre outros aspectos; em outro, a potencialização das formas de organização da opinião pública. Destaca-se, porém, uma tendência calcada com mais ênfase em apenas um dos polos do processo, isto é, na abreviação do potencial democrático dos debates ligados à circulação das notícias no universo das redes, o achatamento da complexidade e a fragmentação dos argumentos oriundos da narração noticiosa e a dissolução dos próprios contratos simbólicos instituídos historicamente em torno da autoridade jornalística (VOS; THOMAS, 2018) - este último, em sintonia com a dissolução da autoridade de um rol mais amplo de instituições sociais que se fizeram fundamentais na modernidade.

\section{Referências}

BARDIN, L. Análise de Conteúdo. Lisboa (Portugal): Edições 70, LDA, 2009.

BORRILLO, D. Homofobia: história e crítica de um preconceito. Belo Horizonte: Autêntica, 2010.

boyd, D. Social Network Sites: Public, Private, or What?. Knowledge Tree, Brisbane, Queensland, n. 13, maio 2007. 
BRASIL. Constituição da República Federativa do Brasil. Brasília: Senado Federal: Centro Gráfico, 1988. CANAVILHAS, J. Del gatekeeping al gatewatching: el papel de las redes sociales en el nuevo ecosistema mediático. In: IRIGARAY, F.; CEBALLOS, D.; MANNA, M. (orgs.). Periodismo Digital: convergencia, redes y móviles. Rosario: Laborde Libro Editor, 2011.

CHEN, G. M. Online incivility and public deliberation. In: LIEBER, C. M.; VOS, T. P. (Org.). Media Scholarship in a Transitional Age. 1a. ed. New York: Peter Lang, 2018, p. 25-38.

COELHO, D. A. A construção social da crítica das práticas jornalísticas no contexto brasileiro: dispositivos críticos na esfera pública em rede. Tese de doutorado (Comunicação), Universidade do Vale dos Sinos (UNISINOS), 2019.

FACEBOOK. Padrões da Comunidade. Disponível em: https://pt-br.facebook.com/communitystandards// Acesso em: 16 jun. 2019.

GÊNERO E NÚMERO. Mapa da violência de Gênero: LGBT+. Disponível em: https:// mapadaviolenciadegenero.com.br/lgbt/. Acesso em: 15 ago. 2020.

HELLER, A. O cotidiano e a história. Rio de Janeiro: Paz e Terra, 1972.

LONGHI, R. R. Narrativas digitales y estructuras circulares. TecCom Studies: Estudios de Tecnología y Comunicación, Madrid, v. 7, 2019.

LOPES, M. I. V. Pesquisa em Comunicação. 8a. ed., São Paulo: Loyola, 2005.

MEYER-PFLUG, S. R. Liberdade de Expressão e Discurso de Ódio. São Paulo: Editora Revista dos Tribunais, 2009.

MONDRAGON, J. M. Intolerance toward Sexuality Diversity and Homophobic Crimes. A Sociological Analysis. Sociologica, Cidade do México, ano 24, n. 69, p. 123-156, jan./abr. 2009.

MORATO, R. S. Os sentidos dos discursos sobre gênero e sexualidade no Facebook: a desigualdade social "curtida” e "compartilhada”. 148 f. Dissertação de Mestrado (Direitos Humanos), Universidade Federal de Pernambuco, 2017.

PESQUISA BRASILEIRA DE MÍDIA 2015. Hábitos de consumo de mídia pela população brasileira. Disponível em: http://www.secom.gov.br/atuacao/pesquisa/lista-de-pesquisas-quantitativas-e-qualitativasde-contratos-atuais/pesquisa-brasileira-de-midia-pbm-2015.pdf. Acesso em: 16 jun. 2019.

QUADROS, P. Dissimulacro-ressimulação: ensejos da cultura do ódio na era do Brasil pós-verdade. Media \& Jornalismo, Lisboa, v. 18, n. 32, p. 201-218, maio 2018.

RECUERO, R. Atos de ameaça à face e à conversação em redes sociais na internet. In: PRIMO, A. (Org.). Interações em rede. Porto Alegre: Sulina, 2013.

RECUERO, R. Curtir, compartilhar, comentar: trabalho de face, conversação e redes sociais no Facebook. Verso \& Reverso, São Leopoldo, v. 28, n. 68, maio/ago. 2014.

RECUERO, R. Disputas discursivas, legitimação e desinformação: o caso Veja x Bolsonaro nas eleições brasileiras de 2018. Comunicação, Mídia e Consumo (Online), São Paulo, v. 16, 2019.

RECUERO, R. Tipologia de Redes Sociais Brasileiras no Fotolog.com. E-Compós, Brasília, v. 9, p. 1, 2007. RECUERO, R.; GRUZD, A. Cascatas de "Fake News” Políticas: Um estudo de caso no Twitter. Galáxia, São Paulo, v. 41, p. 31-47, 2019.

RECUERO, R.; ZAGO, G.; SOARES, F. B. Using Social Network Analysis and Social Capital to Identify User Roles on Polarized Political Conversations on Twitter. Social Media + Society, Thousand Oaks, v. 1, p. 1-20, 2019. 
RIOS, R. R. (org). Em defesa dos Direitos Sexuais. Porto Alegre, Livraria do Advogado, 2007. 195p.

SAINZ, N.; RECUERO, R. O que as páginas dos partidos dizem sobre eles? Análise de redes das páginas oficiais dos partidos políticos brasileiros no Facebook. Revista Debates, Porto Alegre, v. 13, p. 27-57, 2019.

SARMENTO, D. Livres e iguais: estudos de Direito Constitucional. Rio de Janeiro: Lumen Juris, 2006.

SOARES, F. B. et al. Desinformação e esfera pública no Twitter: Disputas discursivas sobre o assassinato de Marielle Franco. Revista Fronteiras (Online), São Leopoldo, v. 3, p. 1-15, 2019.

SOARES, M. C. Jornalismo e cidadania, em duas abordagens. In: VICENTE, M. M. (Org). Comunicação e cidadania. Bauru: Edusc, 2009.

SOUZA MARTINS, J. A sociabilidade do homem simples: cotidiano e história na modernidade anômala. 2.ed. São Paulo: Contexto, 2010.

VOS, T. P., THOMAS, R. The discursive construction of journalistic authority in a post-truth age. Journalism Studies, Londres, v. 19, n. 13, p. 2001-2010, 2018.

ZAGO, G. S. Ressignificações do acontecimento no jornalismo em rede. Observatório, Palmas, v. 3, p. 305326, 2017.

\section{Marcos Paulo da Silva}

Professor da Faculdade de Artes, Letras e Comunicação (FAALC) da Universidade Federal de Mato Grosso do Sul (UFMS). Docente permanente do Programa de Pós-Graduação em Comunicação e do Programa de Pós-Graduação em Estudos de Linguagens da instituição. Doutor em Comunicação Social pela Universidade Metodista de São Paulo (UMESP), com estágio de doutorado sanduíche (PDSE/Capes) na Syracuse University (Nova Iorque, Estados Unidos) E-mail: marcos.paulo@ ufms.br.

\section{Lucas Souza da Silva}

Jornalista graduado e mestrando em Comunicação pela Universidade Federal de Mato Grosso do Sul (UFMS). Bolsista da Coordenação de Aperfeiçoamento de Pessoal de Nível Superior (Capes). Vencedor do Prêmio Adelmo Genro Filho de Pesquisa em Jornalismo 2019, categoria Iniciação Científica. E-mail: lucas_13088@hotmail.com.

Recebido em: 17.11.2019

Aprovado em: 01.09.2020

Este artigo é publicado em acesso aberto (Open Access) sob a licença Creative Commons Attribution Non-Commercial (CC-BY-NC), que permite uso, distribuição e reprodução em qualquer meio, sem restrições, desde que sem fins comerciais e que o trabalho original seja corretamente citado.

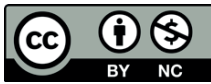

